\title{
Author Correction: Transcriptional profiling and therapeutic targeting of oxidative stress in neuroinflammation
}

Andrew S. Mendiola (D, Jae Kyu Ryu (1), Sophia Bardehle, Anke Meyer-Franke, Kenny Kean-Hooi Ang, Chris Wilson, Kim M. Baeten, Kristina Hanspers (1), Mario Merlini, Sean Thomas, Mark A. Petersen, Alexander Williams (1),

Reuben Thomas, Victoria A. Rafalski, Rosa Meza-Acevedo, Reshmi Tognatta, Zhaoqi Yan, Samuel J. Pfaff, Michael R. Machado, Catherine Bedard, Pamela E. Rios Coronado, Xiqian Jiang (1), Jin Wang (1), Michael A. Pleiss,

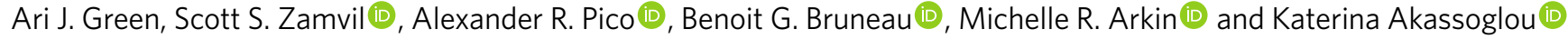

Correction to: Nature Immunology https://doi.org/10.1038/s41590-020-0654-0, published online 13 April 2020.

In the version of this article initially published, in the Competing interests declaration, the competing interests for J.W. and X.J. were omitted. J.W. and X.J. are the coinventors of a patent (WO2016025382A8 and US201462035400P) related to the glutathione probes used in this study. J.W. is the cofounder of CoActigon Inc. and Chemical Biology Probes LLC. The error has been corrected in the HTML and PDF versions of the article.

Published online: 13 July 2020

https://doi.org/10.1038/s41590-020-0754-x

() The Author(s), under exclusive licence to Springer Nature America, Inc. 2020

\section{Publisher Correction: Tumor-necrosis factor impairs CD4+ T cell-mediated immunological control in chronic viral infection}

Marc Beyer, Zeinab Abdullah, Jens M. Chemnitz, Daniela Maisel, Jil Sander, Clara Lehmann, Yasser Thabet, Prashant V. Shinde, Lisa Schmidleithner, Maren Köhne, Jonel Trebicka, Robert Schierwagen, Andrea Hofmann, Alexey Popov, Karl S. Lang, Annette Oxenius, Thorsten Buch, Christian Kurts, Mathias Heikenwalder, Gerd Fätkenheuer, Philipp A. Lang, Pia Hartmann, Percy A. Knolle and Joachim L. Schultze

Correction to: Nature Immunology https://doi.org/10.1038/ni.3399, published online 7 March 2016.

In the version of this article initially published, in Fig. 7d, the flow cytometry plot for the WT cells (left) was incorrectly duplicated. The correct flow cytometry plot for the TNFRI-II-KO cells is shown below (middle). The error has not been corrected in the original article.
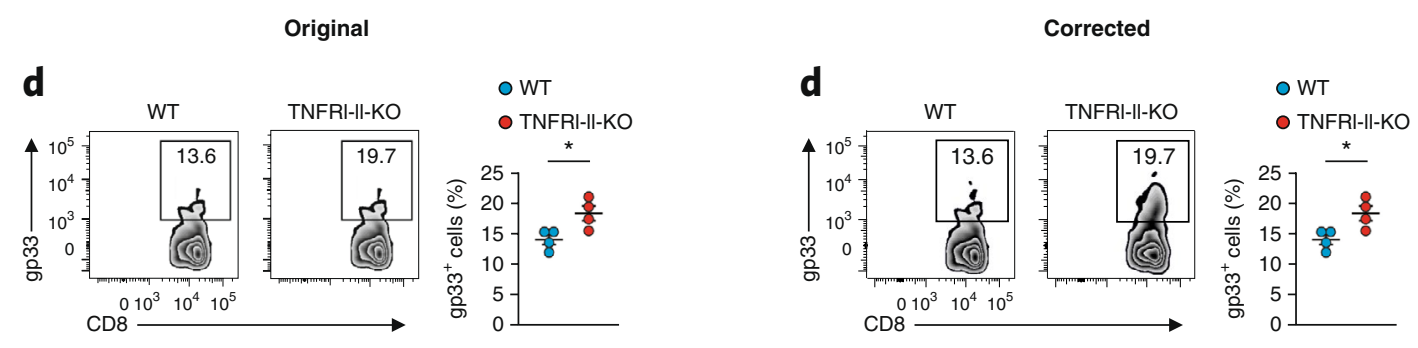

Fig. 7d | Original and corrected.

Published online: 3 July 2020

https://doi.org/10.1038/s41590-020-0749-7

๑ The Author(s), under exclusive licence to Springer Nature America, Inc. 2020 